\title{
Intratextos-
}

\section{CULTURA E IDEOLOGIA: REFLEXÕES SOBRE TRABALHO DOMÉSTICO E SUA REPRESENTAÇÃO NAS TELENOVELAS BRASILEIRAS}

Carla Sellan ${ }^{1}$

\section{RESUMO}

Este artigo busca evidenciar o nexo existente entre a ideologia racista que permeia a divisão sexual do trabalho nas sociedades coloniais, e sua propagação através da moderna Indústria Cultural. Para tanto, observamos o emprego doméstico, que permanece como uma das principais categorias socio-ocupacionais femininas do Brasil, e sua representação nas telenovelas veiculadas pela maior emissora nacional. Considerando a América Latina, o Brasil se destaca entre os países detentores dos maiores contingentes de trabalhadoras domésticas. Além disso, o país consolidou-se, ao longo da segunda metade do século XX, como um dos maiores fabricantes de telenovelas do mundo - atrás apenas do México. A telenovela é o produto mais celebrado da televisão brasileira (e também o mais exportado). Ao tomá-la como objeto de análise, revelamos um sistema simbólico representativo do modo como as elites pensam a categoria das trabalhadoras domésticas, e que contribui ativamente para perpetuação das desigualdades de raça e gênero em nossa sociedade.

PALAVRAS-CHAVE: raça; gênero; trabalho; cultura; representação.

\begin{abstract}
This article aims to highlight the link between the racist ideology that permeates the sexual division of labor in colonial societies, and its propagation through the modern Cultural Industry. To this end, we will analyze the domestic work, which remains one of the largest female sociooccupational categories in Brazil, and its representation in telenovelas produced by the biggest national broadcaster. Considering Latin America, Brazil stands out among the countries that has the largest contingents of domestic workers. Besides that, the country has established itself, throughout the second half of the 20th century, as one of the biggest manufacturers of telenovelas in the world - second only to Mexico. The telenovela is the most popular product of Brazilian television (and also the most exported). By taking it as an object of analysis, we reveal a symbolic system that is representative of the way how the elite think about the category of domestic workers, which actively contributes to the perpetuation of racial and gender inequalities in our society.
\end{abstract}

KEYWORDS: race; gender; work; culture; representation.

\footnotetext{
${ }^{1}$ Doutoranda no Programa de Pós-Graduação em Sociologia Universidade Federal de Pernambuco.
} 


\section{Intratextes -}

\section{Raiz cultural do trabalho reprodutivo no brasil: do entresséculos (XIX-XX) à modernização}

A normatização do trabalho reprodutivo no Brasil é decorrente da ascensão do modelo de família nuclear, representando a resposta da burguesia ao "problema" da "libertação" dos escravizados. Ao contrário do que muitos imaginam, a respeito de um possível abrandamento na ideologia de gênero ${ }^{2}$ na medida em que se "dissolve" a família patriarcal, o modelo econômico imposto durante a modernização estabelecerá distinções ainda mais rígidas entre o trabalho entendido como função feminina, e aquele entendido como função masculina. Os dois papéis devem se integrar em um quadro de aparente complementaridade, visualizado no ideal de família nuclear. A partir daí, conceitos centrais como "maternidade" e "infância" adquirem novo significado, tornando-se estruturantes para o discurso sobre a suposta domesticidade "natural" imputada às mulheres brancas. As crianças brancas passam a ser encaradas como fonte de riqueza em potencial da nação, devendo ser cuidadas e protegidas sob o olhar atento da mãe; e as mulheres brancas passam a ser encaradas como as maiores responsáveis pela educação e civilização de seus filhos, garantindo, assim, o futuro da sociedade (RONCADOR, 2008). Dentro deste quadro, o ethos branco-burguês estabelece uma hierarquia entre as tarefas morais (que são as funções gerenciais, associadas à “dona de casa” branca) e as tarefas manuais (sob responsabilidade de uma trabalhadora negra contratada, ex-escravizada). Conforma-se, desse modo, um programa de divisão racial do trabalho reprodutivo.

\footnotetext{
2 Considero ideologias como formas de estruturação do pensamento (ou sistemas simbólicos) que legitimam/orientam as ações de determinadas classes de sujeitos. Ideologia de gênero diz respeito a um sistema simbólico desenvolvido no interior das classes branco-ocidentais, que determina gramáticas de gênero específicas para indivíduos anatomicamente distintos (classificados diferencialmente como "homens" e "mulheres"). Com o avanço do colonialismo e a consequente imposição da cultura branco-europeia como caractere universal, os construtos sociais "homem" e "mulher" - que trazem consigo modelos específicos de "masculinidade" e "feminilidade" - passam a ser compulsoriamente aplicados aos demais povos. A ideologia de gênero é dinâmica, e sofre reconfigurações que acompanham a classe econômica no poder (por isso, sua atual classificação como ideologia de gênero burguesa). Ela tem impacto direto sobre a maneira como a sociedade se (re)estrutura, em especial, o mercado de trabalho. Para um mínimo entendimento e uso correto do termo, sugiro a leitura dos textos de Margareth Rago ("Do cabaré ao lar: a utopia da cidade disciplinar", 1985) e de Susan Besse ("Modernizando a desigualdade: reestruturação da ideologia de gênero no Brasil", 1999). A análise destas autoras se concentra no período que corresponde ao início do século XX, e ambas tratam do impacto da ideologia de gênero sobre as mulheres brancas brasileiras. A principal diferença entre as abordagens é que, enquanto Rago mantém o foco sobre as mulheres do chamado "proletariado urbano", Besse se atém às mulheres das classes médias. Por fim, recomendo a leitura do texto de Yèrónké Oyěwùmí ("A invenção das mulheres: construindo um sentido africano para os discursos ocidentais de gênero", 2021), sobre a disseminação da ideologia de gênero nas sociedades africanas.
} 


\section{Intratextos-}

O ideal branco-burguês de maternidade pôde associar-se à função civilizadora somente graças ao cumprimento, por uma trabalhadora negra, das "tarefas maternas" consideradas degradantes. Enquanto à mulher branca cabia a tarefa de gerenciar o espaço doméstico e educar seus filhos, ficavam reservadas às mulheres negras as funções consideradas degradantes, como a lavagem das roupas, a limpeza da residência, a higiene corporal das crianças, a preparação dos alimentos etc. Em um período de acirradas mudanças sociais, esse programa tem a dupla função de manter sob controle as mulheres brancas das frações abastadas, restringindo sua participação na vida pública, uma vez que sua presença no "lar" será assinalada como mais crucial do que nunca; além de manter as mulheres negras recém "libertas" desempenhando as mesmas tarefas que lhes eram reservadas no período de escravização institucionalizada.

A construção imaginária da civilizadora mulher doméstica tem como contraponto duas principais figuras: [1] a matrona aristocrata, preguiçosa e corpulenta, modelo de feminilidade dos séculos anteriores, pouco dedicada ao gerenciamento de sua residência e aos cuidados com os filhos, posto que deixava tudo ao encargo dos escravizados; [2] e a mulher negra, trabalhadora doméstica, ex-escravizada. Essa mensagem passa a ser transmitida enfaticamente e de diversas formas. No entresséculos (XIX/XX), a nascente Indústria Cultural brasileira encarrega-se de apresentar ao público os "novos" hábitos que determinam como as coisas devem se passar no relacionamento entre as recém-instituídas "classes" de sujeitos. O "lar" burguês transforma-se em cenário privilegiado da maioria das produções culturais deste período, e o discurso sobre a "domesticidade" torna-se fio condutor de muitos romances de conduta, peças teatrais, manuais de comportamento, guias médicos etc, especialmente voltados ao público brando das frações médias. A regra incutida nestes produtos era bastante clara: quanto mais distinta da trabalhadora doméstica negra estivesse a mulher burguesa, tanto melhor ${ }^{3}$.

Após o fim da escravização institucionalizada, a população negra será eleita como a grande culpada pelo "atraso" nas relações de produção do país. Em decorrência deste procedimento, as domésticas se transfiguram, aos olhos da branquitude, em um obstáculo ao processo de aburguesamento da vida cotidiana que se quis impor na modernidade. Contudo,

\footnotetext{
3 A figura da trabalhadora doméstica negra será utilizada como signo estratégico, para lembrar a mulher burguesa de permanecer vigilante. Tornam-se recorrentes narrativas sobre a doméstica invasora da "privacidade" e da "intimidade" do "lar" (qualidades intrínsecas ao espaço doméstico branco-burguês), assim como a inclusão nesse discurso da trabalhadora doméstica ladra, invejosa e consumidora desautorizada dos bens e hábitos dos patrões. Figuras como a lavadeira e a ama de leite serão especialmente cotadas como signos de contaminação, retratadas como sujas, lascivas e transmissoras de enfermidades (RONCADOR, 2008). Hoje, as mesmas estratégias narrativas podem ser identificadas, conforme pude constatar ao longo desta pesquisa, nas telenovelas contemporâneas, produzidas em larga escala pelas emissoras nacionais.
} 


\section{Intratextes-}

ainda que supostamente incomodada, a burguesia não abre mão dos serviços dessas trabalhadoras, que, apesar de associadas a toda sorte de malefícios, constituem, desde a "libertação" dos escravizados, uma das maiores categorias socio-ocupacionais femininas do país ${ }^{4}$. Com a ascensão do capitalismo industrial, as unidades familiares convertem-se, de manufaturadoras dos bens ainda não disponibilizados no mercado, em puras unidades de consumo, fato que, em tese, deveria ter simplificado bastante o trabalho doméstico. Ainda assim, a necessidade desse tipo de mão de obra não arrefeceu. $\mathrm{O}$ cuidado com as crianças deixou de ser encargo da ama de leite para associar-se à figura da "babá", e a lavagem de roupas será transferida para a "área de serviço" do domicílio burguês, ficando ao encargo de uma "empregada doméstica" 5 , que também deve cuidar do preparo dos alimentos e da limpeza da residência, cabendo à "patroa" a tarefa de gerenciar o seu desempenho.

O projeto burguês de "modernização" das (ex-)colônias consistia em cultivar hábitos "renovados" em sociedades até então marcada pelo atraso que o escravismo passou a representar. Nessa conjuntura, o Brasil - como o país que recebeu mais escravizados no mundo, e como um dos últimos países a "abolir" a escravização - representa um caso bastante característico. Rapidamente, as elites nacionais percebem que, a despeito de suas inúmeras tentativas, o negro não é um elemento que pode ser facilmente apagado, devendo, então, ser “integrado". A partir de movimentos culturais como o modernismo, artistas e intelectuais das frações dominantes buscarão reverter seus julgamentos negativos a respeito da contribuição afroindígena. E, se nas produções culturais do entresséculos a mestiçagem era considerada uma degeneração, nos anos de 1920 e 1930 ela será incorporada como força motriz.

Ícone do imaginário escravocrata, o mito da devotada e afetiva "mãe preta" desaparece gradualmente das produções culturais do século XIX à medida que se popularizava a imagem tida como aterrorizante da ama de leite mercenária, que não se dedica aos seus "filhos de criação"

\footnotetext{
4 O Brasil está, segundo dados da Organização Internacional do Trabalho (OIT, 2010), entre os países latinoamericanos detentores dos maiores contingentes de mulheres trabalhadoras domésticas. A lista inclui Paraguai (com 20,6\% das mulheres ocupadas desempenhando o trabalho doméstico), seguido de Uruguai $(18,6 \%$ ), Argentina (17,3\%), Brasil (17\%) e Chile (14,3\%). Na América Latina, de cada 100 mulheres formalmente ocupadas, 14 estão no emprego doméstico, o que faz com que esta seja considerado a ocupação mais importante para as mulheres dessa região. Fonte: Notas OIT / O trabalho doméstico remunerado na América Latina. Nota 1 Um trabalho decente para as trabalhadoras domésticas remuneradas no continente. Dezembro de 2010. Disponível em: https://www.ilo.org/brasilia/publicacoes/WCMS_229664/lang_pt/index.htm. Último acesso em maio de 2021.

5 O termo "empregada doméstica" é aqui utilizado para ressaltar o paternalismo que segue definindo as relações de trabalho doméstico mesmo após o fim da escravização. Constata-se, hoje em dia, a preferência pelo termo "trabalhadora doméstica", como modo de afirmar o valor social desta ocupação.
} 


\section{Intratextos-}

por sentimentos natos de amor e lealdade, mas por pura obrigação servil e em troca de recompensas monetárias. A partir de 1920, no entanto, o mito da mãe preta retorna ao discurso artístico e intelectual como signo nostálgico de um passado aristocrático em declínio e, mais importante, como símbolo de confraternização inter-racial. Esse mito constitui-se, como bem aponta Sônia Roncador (2008), a partir de alguns dos predicados da mãe burguesa ideal: a percepção do exercício da maternidade como missão natural da mulher, o autossacrifício e abnegação intrínsecos ao exercício dessa missão e a santidade do amor maternal pelos filhos. A mãe preta é a mulher escravizada a quem se destinam os cuidados físicos da criança e da família: a alimentação, a higiene corporal etc. Tais cuidados são, contudo, na construção desse mito, desempenhados à luz de sentimentos "nobres" de lealdade aos seus "senhores". Ou seja, as ações da mãe preta são impulsionadas não pela violência das práticas escravagistas, mas por um gesto "natural" de servilismo intrínseco.

O mito da mãe preta corrobora a falácia existente a respeito da suposta passividade da população negra diante da escravização, "porque, afinal, os senhores de escravos lusobrasileiros foram muito bons e cordiais”, ironiza Lélia Gonzalez (1981b, p.3). A autora aponta a figura da mãe preta como o modelo ideal dessa suposta docilidade, e questiona: afinal, "ela tinha outra escolha? Claro que não, pois era escrava e justamente por isso foi obrigada a cuidar dos filhos de seus senhores". A mãe preta é a face pública que os brancos esperam que as mulheres negras assumam diante deles, escreve Patricia Hill Collins (2019 [1990]). Historicamente, muitas famílias brancas mantêm sua posição de privilégio devido à utilização de trabalhadoras domésticas negras como mão de obra sub-remunerada. A imagem da mãe preta foi concebida para ocultar essa exploração, que retira o trabalho das mulheres negras de suas próprias famílias, negando à família negra tanto o benefício de um salário condizente com suas necessidades quanto o trabalho efetivo que estas mulheres realizariam em suas casas.

Imaginada como uma mulher velha, maternal e obediente, a mãe preta não representa risco à família burguesa, e o seu contraponto pode ser visualizado no estereótipo da mucama, posteriormente ressignificada como "mulata". Caracterizada por sua "natural" sensualidade, a beleza física da mulata evidencia-se principalmente pela supressão de seus traços de negritude, atenuados pela mestiçagem, decorrente da lógica escravagista que estimula o estupro. "É por aí que a gente deve entender que esse papo de que a miscigenação é prova da 'democracia racial' brasileira não está com nada", enfatiza Lélia Gonzalez (op. cit., ibid.). O grande contingente de brasileiros mestiços, argumenta a autora, é resultado do estupro das mulheres escravizadas. Essa 


\section{Intratextos-}

dinâmica racista reverbera na atual visão que a branquitude alimenta a respeito da mulher negra como "mulher fácil”, "boa de cama” etc, pontua Gonzalez (1981b).

Se, por um lado, a dualidade racial da mulata projeta-a como beleza exótica, por outro, sua identidade mestiça não abranda, mas, ao contrário, intensifica a visão negativa do seu sexo. $\mathrm{Na}$ ideologia romântica do patriarcado brasileiro, a experiência erótica, ou o prazer sexual, somente se consuma quando o corpo mestiço entra em cena. A indeterminação racial da mulata reflete, no plano da sexualidade, o efeito desestabilizador de seus dotes "sedutores", e ela não transmite o mesmo grau de distanciamento e inacessibilidade do corpo feminino branco, que, segundo os preceitos cristãos, não deve rebaixar-se aos pecados da carne. A hierarquização do desejo segundo o objeto feminino de cobiça - amor casto/amor carnal - reforça a matriz organizacional assinalada por Freyre, ao estabelecer os papéis ocupados pela mulher no escravagismo brasileiro: "branca para casar, mulata para foder e negra para trabalhar" (2003 [1933], p.72). A mulher de pele preta é a mãe, utiliza-se para o trabalho físico de cuidado das crianças e da casa; a mulher mestiça é a amante, utiliza-se para satisfação sexual; a esposa branca é a reprodutora, que garante a perpetuação da linhagem.

Assim como a mãe preta, a mulata cordial circula no imaginário da burguesia como símbolo de "integração" - de acordo com os moldes definidos pela branquitude sobre qual o tipo específico de "integração" disponível às mulheres negras -, contudo, estes símbolos não têm nenhuma relação com uma identidade autodefinida pelas mulheres negras ou mesmo com um projeto autêntico de valorização da identidade negra. A escrita de autores como Gilberto Freyre baseia-se em um suposto gesto de "afirmação" das culturas afro-brasileiras, que deve ser entendido mais como um gesto de localização dentro do universo simbólico da branquitude, e não de autodefinição/autovalorização destas culturas. A evocação nostálgica dos escravizados, mediada pela falsa retórica de parentesco, é um mecanismo recorrente ao modernismo. Neste processo, as violências inerentes ao escravagismo serão removidas e/ou atenuadas, para que estes estereótipos possam servir convenientemente a uma narrativa utópica de confraternização inter-racial. Revelando sua adesão ao hábito senhorial, evidencia-se a fidelidade e o real compromisso dos produtores destes mitos com a sua casta de origem (RONCADOR, 2008).

A disseminação destes mitos tem efeito perverso sobre as mulheres negras, que terão sua imagem conformada com base em duas matrizes: o estereótipo da "mulata" (o uso sexual) e da trabalhadora doméstica (o uso físico). E é por isso, explica Lélia Gonzalez (1984), que "os termos mulata e doméstica são atribuições de um mesmo sujeito" (p.228). A autora menciona 


\section{Intratextes-}

as continuidades históricas inerentes a esta lógica, assinalando que as mulheres negras permanecem preferencialmente confinadas ao desempenho de atividades precarizadas, em funções que agregam tarefas circunscritas ao âmbito do chamado trabalho reprodutivo ou de cuidado, geralmente desenvolvidas na informalidade. O termo "doméstica", observa Gonzalez (1979a), abrange não apenas a trabalho realizado nas residências burguesas, mas toda uma série de ocupações que demarcam um "lugar natural" para a trabalhadora negra: "merendeira na rede escolar, servente nos supermercados, na rede hospitalar etc" (p.16).

Hoje, no Brasil, o emprego doméstico permanece como uma das principais portas de acesso ao trabalho remunerado disponível às mulheres negras. É verdade que, em nosso país, para as mulheres negras, tanto quanto para as mulheres brancas, a desigualdade de gênero no mercado de trabalho ainda se revela de forma consistente. Entretanto, também é verdade que os dados sobre tal desigualdade se tornam mais expressivos conforme observamos a variável racial. As mulheres, mais que os homens, e as mulheres negras, mais que as mulheres brancas, são aquelas que devem desempenhar as funções mais desvalorizadas, além de serem maioria na informalidade ${ }^{6}$. Debruçando-nos sobre os dados que tratam especificamente do emprego doméstico, percebemos discrepâncias mais explícitas. De acordo com a última Pesquisa Nacional por Amostra de Domicílios (PNAD) - dados detalhados por Sarris et al. (2020) -, a maioria das mulheres atuantes nessa profissão é negra (65,3\%), e a proporção é um pouco maior se levarmos em conta o grau de formalização $(66,4 \%$ das trabalhadoras domésticas sem carteira assinada são negras). Devo ressaltar que este emprego ainda é majoritariamente exercido na informalidade: $74 \%$ das trabalhadoras domésticas não possui registro formal. As trabalhadoras domésticas sem registro recebem um salário médio de $\mathrm{R} \$ 774,00$, já as com carteira assinada receberam uma média de $\mathrm{R} \$ 1.292,00$ mensais.

\footnotetext{
6 De acordo com o IBGE, tomando por base a população com 25 anos ou mais, 23,5\% das brasileiras possuem ensino superior completo. Entre os homens o percentual é menor: $20,7 \%$ possuem ensino superior completo. Contudo, estes resultados não refletem na renda mensal da população feminina: entre os anos de 2012 e 2016, a mulher ainda ganhava, em média, $75 \%$ do que ganhava o homem. A pesquisa também confirma a desigualdade existente no acesso à educação entre mulheres negras e brancas: mulheres brancas concluem o ensino superior em proporção 2,3 vezes maior que as mulheres negras. O estudo aponta que as desigualdades relativas ao gênero podem estar relacionadas à predominância feminina na realização do trabalho reprodutivo. No geral, o tempo dedicado a estas tarefas é maior entre as mulheres (18,1 horas semanais) do que entre os homens (10,5 horas semanais), mas são as mulheres negras que têm mais do seu tempo consumido por estas atividades: são 18,6 horas semanais, em comparação às 17,7 horas gastas pelas mulheres brancas. O Nordeste é a região do país onde as mulheres dedicam um número maior de horas aos serviços domésticos (19 semanais). As mulheres também são maioria $(28,2 \%)$ no emprego informal - homens $(14,1 \%)$-; observando-se a variável raça, $31,3 \%$ das mulheres negras está no trabalho precário, já entre as mulheres brancas, o percentual é de $25 \%$. Fonte: Estatísticas de gênero - indicadores sociais das mulheres no Brasil (IBGE, 2018). Disponível em: https://biblioteca.ibge.gov.br/visualizacao/livros/liv101551_informativo.pdf. Último acesso em maio de 2021.
} 


\section{Intratextos-}

No período pós-escravização, os homens negros eram mais vulneráveis ao desemprego e a demissão, uma vez que competiam diretamente com os homens brancos (nacionais e estrangeiros). Neste cenário, aponta Florestan Fernandes (2008 [1964]), a mulher negra teria uma suposta "vantagem", pois logrou enfrentar o período de transição entre a escravatura institucionalizada e o capitalismo dependente "sem perder onde trabalhar", porém, "não no sentido de achar um aproveitamento ideal ou decididamente compensador", escreve o autor, "mas, por ser a única a contar com ocupações persistentes e, enfim, com um meio de vida" (p.83). Por "ocupações persistentes" entende-se a já mencionada manutenção das mulheres negras no trabalho doméstico. É importante perceber que, embora encontrassem maiores dificuldades em conseguir ocupações, quando empregados, os homens negros recebiam melhores salários, em comparação à remuneração substancialmente mais baixa recebida pelas mulheres negras no trabalho doméstico. Esse padrão clássico de exploração, diferenciado por gênero, com frequência tem sido deturpado por argumentos que sugerem que as mulheres negras ou os homens negros têm "vantagem" no mercado de trabalho em relação um ao outro. O que essas abordagens parecem não levar em conta é que ambos, mulheres e homens negros, foram desfavorecidos no mercado de trabalho urbano, no qual diferenças raciais e de gênero estruturam padrões distintos de vulnerabilidade econômica no emprego (COLLINS, 2019).

Para as mulheres brancas dos estratos sociais médios e das elites, a entrada no mercado de trabalho se inicia a partir da década de 1910, quando passam a fazer parte, junto com as mulheres brancas em situação de pobreza, da mão de obra assalariada. A partir daí, faz-se necessária a instituição de novos padrões de "emprego feminino", que vão se consolidando ao longo das décadas seguintes. A ausência das mulheres brancas no "lar" representava um obstáculo aos esforços para promover a organização social considerada adequada pela ideologia de gênero burguesa. Surge a questão de como conciliar o emprego das mulheres brancas no mercado formal com a necessidade de ligá-las aos seus deveres "familiares", preservando o ideal de divisão sexual do trabalho. Como forma de atenuar as contradições, o emprego assalariado das mulheres brancas deveria definir-se como extensão de seus papéis familiares, restringindo-se seu ingresso em trabalhos considerados "inadequados"7. As mulheres brancas

\footnotetext{
7 No Brasil, o tipo de emprego inicialmente destinado às mulheres brancas não lhes possibilita deixar de lado seus papéis familiares, nem contesta os estereótipos que vinculam a feminilidade branca à características como delicadeza, virtude e altruísmo. Era crucial para a estabilidade da "família" e essencial para os empregadores (que buscavam manter baixos os custos de mão de obra) que o emprego destinado às mulheres brancas continuasse a ser entendido como "complementar" ao dos homens brancos. O Código Civil de 1916 concedia às mulheres casadas o direito de dispor livremente de seu salário, mas elas eram proibidas de aceitar empregos assalariados
} 


\section{Intratextos-}

das frações médias estavam "naturalmente" qualificadas para preencher os novos postos de professoras, enfermeiras, assistentes sociais, balconistas, caixas de banco, telefonistas, recepcionistas e secretárias; além dos cargos já ocupados pelas mulheres brancas em situação de pobreza, nas indústrias têxtil e de produção de “objetos finos”. Gradativamente, o emprego assalariado passou a ser incluído entre os deveres da mulher branca moderna. As que eram casadas e tinham filhos, deviam sua liberdade de seguir uma "carreira" às trabalhadoras domésticas negras por elas contratadas em regime de sub-remuneração (BESSE, 1999).

Conforme pontua Beatriz Nascimento (1976), a moderna sociedade brasileira apresentase como mais dinâmica no que concerne à diversificação das atividades produtivas, como efeito do processo de industrialização demarcado no período de 1930. Com a expansão industrial e do setor de serviços, a estratificação social, profundamente polarizada no período de escravização, passará a apresentar uma maior “flexibilidade”. No entanto, tal flexibilidade ainda conserva certas determinações de papéis atribuídos aos diferentes grupos sociais. Inúmeros fatores contribuem para perpetuação destas permanências, e o maior deles, como não poderia deixar de ser, em uma sociedade de base escravocrata, é o fator racial. A crescente necessidade de mão de obra para a indústria e outros serviços recentes torna necessário o recrutamento das mulheres. Na fase inicial da industrialização, a mulher branca em situação de pobreza participa da força de trabalho; contudo, com o declínio das indústrias tradicionais, principalmente a têxtil, ela se vê expulsa do setor industrial, passando a ocupar empregos burocráticos de nível mais baixo que, embora mal remunerados, exigem certa qualificação educacional. Em seguida, vem o movimento descrito no parágrafo anterior, quando as mulheres brancas das frações médias passam a fazer parte do setor de serviços, ocupando as já mencionadas “atividades femininas". O mesmo não ocorre com a mulher negra, e isso por dois motivos, de acordo com Beatriz Nascimento: [1] até este ponto, a mulher negra ainda não teve acesso suficiente à educação formal e; [2] esses empregos implicam a chamada "boa aparência" que, no linguajar racista, significa uma aparência branca. A confluência destes fatores mantém a mulher negra em

\footnotetext{
sem a permissão dos maridos. As "leis protetoras" da década de 1930 - peça importante no empenho do governo Vargas para angariar apoio do operariado urbano - avançaram no sentido de restringir o emprego das mulheres brancas, que passam a ser proibidas de atuar em funções que pudessem pôr em perigo sua saúde física, prejudicar a maternidade ou comprometer sua moralidade. Elas não podiam, por exemplo, trabalhar entre as dez horas da noite e às cinco da manhã. Também era proibido às mulheres brancas carregar pesos considerados excessivos, trabalhar em locais subterrâneos e em construção civil, ou ter empregos considerados "perigosos e insalubres". Tais medidas, que visavam "proteger a mulher", conferiam ao operariado masculino o monopólio dos cargos com melhor remuneração (BESSE, 1999).
} 


\section{Intratextes-}

funções historicamente determinadas, como os trabalhos doméstico e agrícola, ou, em menor escala, como operárias industriais.

Em uma sociedade fundada a partir do escravagismo, o quesito "competência técnica" pode ter preponderância sobre o racismo? Melhor dizendo: não seriam estas duas condições a exigência pela qualificação educacional formal (de base europeia) e a exigência por uma "boa aparência" (a aparência branca) - sintomas da mesma patologia (o racismo)?

O "milagre econômico" dos anos de 1969-1973 beneficiou alguns setores da sociedade, mas, de forma geral, não favoreceu significativamente a população negra. O setor terciário de ocupações formais se esforça em "integrar" as mulheres negras em ocupações equivalentes ao trabalho reprodutivo, como os chamados "serviços gerais", que agregam funções de limpeza e manutenção dos ambientes; ou em "serviços de cozinha", que envolvem preparar e servir alimentos. Há, de fato, o fortalecimento de uma fração intermediária negra (economicamente falando), uma vez que, mesmo em considerável menor proporção - comparativamente aos brancos -, mulheres e homens negros conseguiram acesso ao trabalho industrial e burocrático. A maioria, entretanto, permaneceu em serviços de baixa remuneração. Combinadas, essas mudanças segmentam as mulheres negras trabalhadoras em dois subgrupos: uma minoria que possui empregos estáveis em setores públicos e privados; e uma maioria que apenas consegue empregos intermitentes e mal remunerados.

Analisando a sociedade brasileira, Lélia Gonzalez (1979b, p.2) chama atenção para a existência de uma divisão racial do trabalho, ressaltando que não é por coincidência que a maioria da população negra brasileira faz parte de uma massa marginal crescente, que engloba desempregados e trabalho informais. A precarização do trabalho tem impacto direto sobre as baixas condições de vida experienciadas por essa população. Lélia assinala que, mesmo nos dias atuais, em que se constata significativa melhoria quanto ao nível educacional, o que se observa é que a população negra, especialmente a mulher negra, permanece preterida, "por maior que seja a capacidade que demonstre" (1979a, p.14). Essa discriminação se deve, em maior parte, ao supracitado sistema de representações, que Gonzalez chama de racismo cultural, e que naturaliza o fato de a mulher negra desempenhar papéis sociais desvalorizados.

\section{A doméstica imaginada}




\section{Intratextos-}

A telenovela brasileira se desenvolve, ao longo da segunda metade do século XX, como vitrine viva do estilo de vida que se deseja impor na modernidade (o estilo de vida brancoburguês). A TV chega ao Brasil em 1950 e, já no ano seguinte, 1951, vai ao ar a primeira telenovela nacional (Sua Vida Me Pertence, TV Tupi). O produto foi inicialmente entendido como entretenimento para as elites, e os roteiristas brasileiros iniciaram suas carreiras criativas tendo como função principal selecionar e adaptar estórias de sucesso provenientes de outros países da América Latina - nessa fase, ganham especial destaque os roteiros cubanos, em razão da forte tradição de radionovela já consolidada naquele país. Foi a Rede Globo que rompeu com o ciclo de textos estrangeiros, no decorrer dos anos de 1970, direcionando o foco aos "dramas reais" da população brasileira. A emissora buscou desenvolver novas linguagens para a telenovela, por meio do "abrasileiramento" do gênero e de uma maior aproximação da vida cotidiana, incorporando temas emergentes de uma sociedade que se urbaniza e industrializa. A partir daí, a telenovela transformou-se no principal produto da Globo, sendo a grande responsável por sua ascensão à emissora mais popular do país ${ }^{8}$.

Do ponto de vista do homem que fundou o departamento de criação da Rede Globo, Homero Sánchez, a "família” permanece como o valor principal nas narrativas das telenovelas da emissora, e as "mulheres" como figuras centrais na sua manutenção. Há, por isso, noções sobre "feminilidade" e "maternidade" que os roteiristas estão proibidos de questionar. Sánchez ressalta que as novelas devem, preferencialmente, retratar famílias chefiadas por mulheres que criam os filhos sozinhas, porque esse é o tipo de família que compõe a realidade social brasileira, mas confessa que os roteiros permanecem leais à noção de que a estrutura familiar "ideal" é nuclear, organizada em torno de mãe, pai e filhos. Ele também afirma o pressuposto (tomado como certeza) de que as mulheres, especialmente as "donas de casa", constituem o segmento do público mais disponível para assistir televisão em geral e novelas em particular (HAMBURGER, 2005). A “teoria” defendida por Sánchez não possui embasamento empírico, e apoia-se apenas no senso comum, fomentado pela ideologia de gênero burguesa, segundo o qual as mulheres dispõem de mais tempo para entretenimento (pois supostamente não trabalham tanto quanto o homem), além de serem mais afeitas aos divertimentos efêmeros devido às

\footnotetext{
8 Kehl (1986) discute a posição da Rede Globo em relação ao Estado brasileiro e à ditadura militar, destacando o momento de consolidação de um mercado consumidor no Brasil através da televisão. De acordo com a autora, os militares investiram fortemente na formação de uma rede de telecomunicações, objetivando um projeto de integração nacional. A Rede Globo foi a maior beneficiária destes investimentos, tendo sido a primeira emissora autorizada a transmitir para todo o país. A primeira exibição em escala nacional ocorre em setembro de 1969, com a estreia do Jornal Nacional.
} 


\section{Intratextes}

especificidades de sua biologia. Obviamente, a teoria feminista já se esforçou suficiente em desmistificar argumentos como este.

No campo específico da pesquisa social em comunicação, já existe o entendimento de que a telenovela nacional é consumida pela população em geral, independente de gênero ou estratificação socioeconômica ${ }^{9}$. Contudo, dentro das grandes emissoras de televisão brasileiras, ainda se incentiva a noção de que os extratos sociais subalternizados (as chamadas classes $\mathrm{C}$ e D) seriam os mais importantes do ponto de vista da audiência. Entretanto, apesar das mulheres das frações economicamente exploradas (em sua maioria, mulheres negras) serem definidas como público-alvo, os grupos de pesquisas de opinião, que guiam a produção dos roteiros, reúnem apenas mulheres de classe média. Considerando, ademais, que os principais responsáveis pela composição das telenovelas (roteiristas, diretores, produtores, atores etc) são recrutados das frações médias, é fácil deduzir o tipo de ideologia, de visão de mundo, ou de valores culturais, predominantes nestes produtos.

A figura da trabalhadora doméstica é presença constante na Indústria Cultural brasileira, e já foi tema de algumas análises, que chamam atenção por suas semelhanças ${ }^{10}$. Os levantamentos sugerem que, de maneira geral, as domésticas são retratadas pela chave da comicidade, como mulheres ingênuas e inábeis, e sua existência restringe-se, na maior parte das vezes, a servir os patrões. Esse sistema deve ser lido como expressão do modo como a burguesia nacional compreende essa categoria profissional, e expressa questões valiosas para a análise da vida social brasileira. Sendo o produto audiovisual nacional mais exportado para o mundo, tendo massiva receptividade entre os países das Américas, com os quais há intenso intercâmbio de narrativas, observá-lo permite a compreensão de códigos e lugares que integram um sistema simbólico transnacional ${ }^{11}$.

\footnotetext{
9 Neste quesito, destaco as pesquisas de Lopes, Borelli e Resende ("Vivendo com a telenovela: mediações, recepção, teleficcionalidade", 2002) e de Lilia Junqueira ("Desigualdades sociais e telenovelas: relações ocultas entre ficção e reconhecimento", 2010).

10 Há uma infinidade de material publicado sobre essa temática. Para apreciação inicial, sugiro a leitura do texto de Sônia Roncador ("A Doméstica Imaginária: literatura, testemunhos e a invenção da empregada doméstica no Brasil", 2008), que trata especialmente da representação da trabalhadora doméstica na literatura do entresséculos (XIX-XX), nos primórdios da Indústria Cultural nacional, antes do advento do cinema e da TV. Recomendo também a leitura do texto de Joel Zito Araújo ("A Negação do Brasil: o negro na telenovela brasileira", 2004), que trabalha de forma consistente a questão da representação da trabalhadora doméstica nas telenovelas nacionais exibidas ao longo da segunda metade do século XX.

11 O campo dos estudos de telenovela se popularizou no Brasil a partir da primeira década dos anos 2000 (veja a Nota 8), seguindo a tendência dos chamados "estudo culturais" (Stuart Hall, "Encoding and Decoding in the television discourse", 1973) e dos "estudos de recepção" (David Morley, "Family Television: Cultural Power and Domestic Leisure", 1986), proeminentes na sociologia estadunidense a partir da segunda metade do século XX. No campo dos chamados estudos da mídia, especificamente no que concerne ao papel desempenhado pelas
} 


\section{Intratextes-}

O exame do percurso de rejeição e adesão das trabalhadoras domésticas como heroínas na teledramaturgia brasileira evidencia que essa "aceitação" não foi facilmente "conquistada". A primeira novela da Rede Globo protagonizada por uma trabalhadora doméstica foi ao ar em 1974. Em Supermanoela, Marília Pêra interpreta uma jovem doméstica que se dispõe a trabalhar sem remuneração e ajudar a patroa, uma "ex-rica" que declarou falência, a transformar o casarão onde vivem em um pensionato. No início da década de 1970, a telenovela deixa de ser entendida como entretenimento exclusivo para as elites. A Globo considera-se pronta para investir em tramas supostamente mais realistas, mas essa primeira tentativa de inserir a trabalhadora doméstica como heroína foi desastrosa. A baixa audiência de Supermanoela fez Walter Negrão, autor da produção, retirar o foco da personagem-título e reorientá-lo para os estudantes que viviam na pensão.

No ano seguinte, 1975, a Globo decidiu experimentar novamente a fórmula, mas utilizando uma receita antiga: a mulata cordial. A emissora apresenta Sônia Braga, em um dos mais conhecidos episódios de blackface ${ }^{12}$ da televisão brasileira, dando vida a personagemtítulo Gabriela, imaginada pelo romancista Jorge Amado. A história se passa na década de 1920, e narra o "caso de amor" entre o burguês Nacib, dono de um bar, e a retirante Gabriela, que ele encontra em situação de miséria e decide contratar como doméstica. Jorge Amado foi um dos maiores responsáveis pela consolidação do mito da mulata cordial, ao longo das mais de 300 páginas de seu romance, ele ressalta incansavelmente os atrativos sedutores e a "faceirice" de Gabriela. A adaptação de Walter Avancini teve ampla aceitação, principalmente devido ao seu teor “erótico e provocante", e foi reprisada quatro vezes $(1979,1980,1982,1989)$. Gabriela foi a primeira telenovela da Globo a ser exibida em Portugal, invertendo o tradicional ciclo de produção que costuma partir da metrópole para a colônia.

Em 1976, estreia Anjo Mau, e ressurge o mito da trabalhadora doméstica invasora, invejosa e destruidora da paz do lar burguês. Esse é o primeiro trabalho de Cassiano Gabus Mendes para a Globo, e fez muito sucesso. Em Anjo Mau, a iniciante Susana Vieira interpreta Nice, uma moça ambiciosa e que não se conforma em desempenhar funções subalternas. A

tecnologias de comunicação no intercâmbio cultural que se desenvolve dentro da América Latina, as grandes referências são Jesús Martín-Barbero ("Oficio de cartógrafo: travesias latinoamericanas de la comunicación en la cultura", 2002) e Néstor García Canclini (“Las industrias culturales en la integración latinoamericana", 1999). 12 Blackface é uma prática racista que se popularizou no teatro estadunidense, no século XIX, quando era comum que atores brancos colorissem a pele com carvão para representar personagens negros de forma estereotipada. Vale lembrar que o nome da atriz Vera Manhães foi inicialmente cotado para interpretar a personagem Gabriela, mas ela foi rejeitada por não possuir o "tipo físico" considerado adequado. Vera foi substituída por uma atriz branca, Sônia Braga, que precisava ser excessivamente maquiada até atingir o tom de pele entendido como ideal. 


\section{Intratextes -}

jovem começa a trabalhar como babá para uma família de milionários, imaginando que essa pode ser sua chance de ascender socialmente. Nice aproveita as descobertas que faz na mansão para fomentar intrigas e tentar se aproximar do patrão, um homem "fino, sensível e educado", por quem nutre uma paixão obsessiva. O clímax da novela se deu no capítulo da morte da personagem, que obteve os maiores índices de audiência daquela temporada.

Em 1977, após os sucessos Gabriela e Anjo Mau, A Globo sentiu-se "segura” para lançar um debate mais "direto" sobre a questão do emprego doméstico. Sem Lenço, Sem Documento, de autoria de Mário Prata, narrava a história de quatro irmãs nordestinas que migram para o Rio de Janeiro em busca de oportunidades. Apesar do tom ameno, o enredo provocou reações negativas por parte das mulheres da elite pernambucana ${ }^{13}$. Mario Prata mostrou-se receoso e, mesmo afirmando que a trama buscava representar de maneira menos polêmica possível a realidade desta classe trabalhadora, a baixa audiência levou-o a reestruturar o roteiro, diminuindo pela metade o número de personagens.

Depois dessa rejeição, a figura da trabalhadora doméstica só voltará a receber protagonismo na emissora vinte anos depois, em 1997, com a refilmagem de Anjo Mau, dessa vez estrelada por Glória Pires, e com roteiro de Maria Adelaide Amaral. O remake também fez enorme sucesso, tendo sido reprisado duas vezes, em 2003 e em 2016. Mais treze anos depois, em 2010, a trama de Escrito nas Estrelas, de autoria de Elizabeth Jhin, traz o tema do "triângulo amoroso" entre trabalhadora doméstica, patrão e filho do patrão. Até que chega 2012, com o reavivamento do debate sobre a regulamentação do emprego doméstico no Brasil, que inspirou a Rede Globo a lançar, só naquele ano, quatro novelas protagonizadas por trabalhadoras domésticas: Lado a Lado (18h), Cheias de Charme (19h), Avenida Brasil (21h) e Gabriela (23h). Quatro novelas em um ano é um verdadeiro recorde, se considerarmos que das mais de 300 novelas produzidas pela emissora desde 1965 até agora, 11 trazem trabalhadoras domésticas em papéis de protagonismo ${ }^{14}$.

Dentre as novelas lançadas em 2012, o maior sucesso, sem dúvidas, é Cheias de Charme. Escrita por Filipe Miguez e Izabel de Oliveira, a trama é protagonizada pelas trabalhadoras

\footnotetext{
13 Mario Prata recebeu um "manifesto" assinado por 98 patroas de Olinda (PE). As mulheres diziam "protestar violentamente" contra a exposição em horário nobre de personagens classificadas como "escórias da sociedade", e que, "vindas de Olinda", desclassificavam o lugar, passando a impressão de que "nada mais que 'domésticas' podem vir a ser no Sul, como se só isso pudéssemos exportar" (apud MACEDO, 2013, p. 100).

14 Dados obtidos através de levantamento realizado pela autora nos portais Memória Globo - Novelas: https://memoriaglobo.globo.com/entretenimento/novelas/, e Gshow Novelas: https://gshow.globo.com/novelas/. Último acesso em maio de 2021.
} 


\section{Intratextos -}

domésticas Penha (Taís Araújo), Rosário (Leandra Leal) e Cida (Isabelle Drummond), que conseguem ascensão social através de seus dons artísticos. A proposta musical e a comicidade exagerada realçavam o tom da novela, que vinha também carregada de merchandising social. O tema da regulamentação do emprego doméstico foi amplamente explorado pelos autores e, durante o período de veiculação da novela, a Globo exibia, nos intervalos da programação diária, uma campanha gravada através de uma parceria com a Organização Internacional do Trabalho (OIT) e a ONU Mulheres, incentivando trabalhadoras a conhecerem seus direitos e patroas a contratem dentro da lei, o vídeo é protagonizado por Penha e sua patroa, a advogada Lygia (Malu Galli) ${ }^{15}$. As "boas intenções" por parte da emissora, no entanto, não bastaram para livrar Cheias de Charme do olhar crítico das trabalhadoras. O Sindicato das Trabalhadoras Domésticas do Rio De Janeiro interpôs uma ação civil pública por danos morais coletivos contra a Rede Globo em razão da música "Vida de Empreguete", cantada pelas protagonistas. De acordo com a presidente do STD-RJ, Anastácia Oleari, diversas trabalhadoras procuraram o sindicato para reclamar sobre a rotina que é retratada nos versos da canção. Anastácia alega que “o neologismo ‘empreguete' aniquila a importância social de nosso trabalho e ainda nos expõem a trocadilhos infames" (apud SOUZA \& DALBETO, 2013, p. 123). Cheias de Charme foi reprisada pela primeira vez em 2016, batendo recordes de audiência.

Avenida Brasil, na faixa das $21 \mathrm{~h}$, fez quase tanto sucesso quanto Cheias de Charme, alcançando índices superiores em recepção fora do Brasil. Escrita por João Emanuel Carneiro, a trama é centrada na história de Nina (Débora Falabella), uma jovem chefe de cozinha que se "disfarça" de trabalhadora doméstica para vingar-se de Carminha (Adriana Esteves), a madrasta que a abandonou, ainda criança, em um lixão. A tensão resultante da rivalidade entre as duas protagonistas, que nunca conseguiam vencer definitivamente uma a outra, garantia a fidelidade do público. Um dos capítulos de maior audiência foi o episódio da inversão de papéis entre as duas personagens, eternizado na fala polêmica de Nina, dirigindo-se a Carminha: "Me serve, Vadia! Me serve!"16. Avenida Brasil também apresentava outra trabalhadora doméstica que caiu no gosto do público: Zezé (Cacau Protásio), que é uma releitura de mãe preta com um toque de

\footnotetext{
15 Assista em "Cheias de Charme valorizou o trabalho das empregadas domésticas", disponível em: http://redeglobo.globo.com/globocidadania/nas-novelas/noticia/2012/10/cheias-de-charme-valorizou-o-trabalhodas-empregadas-domesticas.html. Último acesso em maio de 2021.

16 O simulacro da "troca de papéis" entre patroa e trabalhadora doméstica é uma constante nas telenovelas brasileiras. Nesse momento, a personagem da trabalhadora assume um tom autoritário e vingativo contra sua até então patroa, que passa a servi-la. Esse tipo de encenação representa o terror que as elites sentem em ver praticadas contra si as arbitrariedades que impõem aos "seus empregados".
} 


\section{Intratextes-}

irreverência e comicidade, característico dos roteiros mais atuais. Embora fosse constantemente humilhada pela vilã Carminha, ela mantinha-se fiel à patroa, permanecendo como sua cúmplice até o fim. Avenida Brasil foi reprisada pela primeira vez em 2019.

Das quatro novelas, a que teve pior aceitação foi Lado a Lado, na faixa das $18 \mathrm{~h}$. Escrita por João Ximenes Braga e Cláudia Lage, a trama é ambientada no início do século XX, e é especialmente focada na condição da mulher negra no pós-abolição. Os pais de Isabel (Camila Pitanga) foram escravizados, mas ela nasceu livre, e trabalha como doméstica na casa de uma madame, onde aprende a "boa educação" europeia. No desenrolar da trama, após engravidar e ser rejeitada por um homem branco, a personagem abandona o trabalho doméstico, tornandose uma das precursoras do samba durante o nascimento do Teatro de Revista. Lado a Lado foi sucesso de crítica, angariando prêmios internacionais devido a sua suposta "preocupação" com a historicização do contexto pós-Abolição, contudo, em termos de audiência, foi um desastre.

Apesar das tramas aparentemente progressistas de Lado a Lado, Cheias de Charme e Avenida Brasil, a Globo não passou todo o ano de 2012 sem reavivar explicitamente mitos tradicionais. Naquele ano, a emissora também traz de volta a mulata cordial, com o remake de Gabriela, desta vez escrito por Walcyr Carrasco. Nesta readaptação, os produtores recorrem novamente ao blackface, escalando uma atriz branca para interpretar a personagem principal. Juliana Paes carecia de maquiagem excessiva para enquadrar-se no tom de pele "cravo e canela", imaginado como adequado ao estereótipo da mulata, o que gerou comentários do público.

\section{Uma nova novela, mas nem tanto}

Ironicamente (ou não), a primeira personagem trabalhadora doméstica a receber status de heroína, ganhando projeção no imaginário nacional, foi interpretada por uma atriz de pele preta. Em dezembro de 1964, estreava O Direito de Nascer (TV Tupi), adaptação do melodrama cubano de Féliz Caignet, que conta a história de Albertinho, jovem branco, recém-formado em medicina, que fora adotado ainda bebê pela trabalhadora doméstica Maria Dolores (Isaura Bruno), a Mamãe Dolores, como ficaria conhecida. Sucesso entre o público, a personagem ganhou popularidade devido ao seu gênio "maternal e protetor", disposta a tudo para preservar o segredo da origem de Albertinho, e evitar a perda daquele que para ela se tornou um filho legítimo. Em seu trabalho sobre a invisibilidade do negro na teledramaturgia brasileira, Araújo (2004) identifica uma séria de modelos de representação recorrentes para as domésticas, o mais 


\section{Intratextes-}

tradicional, ele aponta, é o da mammie, a mãe preta, tão visível na personagem interpretada por Isaura Bruno, e que também pode ser identificado em produções recentes do cinema burguês, como a trabalhadora doméstica Val, interpretada por Regina Casé no filme de Anna Muylaert (Que Horas Ela Volta?, 2015, África Filmes/Globo Filmes). Tradicionalmente, a mulher imaginada para representar mammie deveria ser uma atriz grande e robusta, capaz de caracterizar uma mulher negra ao mesmo tempo orgulhosa e autoritária, mas, sobretudo, carinhosa e maternal. A versão contemporânea da mammie diferencia-se do modelo tradicional principalmente no aspecto físico, sendo representada por atrizes mais magras e com traços de negritude atenuados pela mestiçagem, mas sempre caracterizada como uma doméstica generosa e abnegada. Que Horas Ela Volta? alcançou grande sucesso de público e crítica, evidenciando como a parcela da burguesia nacional que se acredita progressista permanece sensivelmente apegada ao estereótipo da mãe preta.

No final de 2019, sete anos após a última investida no campo das telenovelas, a Globo iniciou a exibição de mais uma trama protagonizada por trabalhadora doméstica ${ }^{17}$. Em Amor de Mãe (2019) Regina Casé interpreta Lurdes, uma nordestina que migra para o Rio de Janeiro em busca do filho perdido. O título da trama sugere o reavivamento do tradicional mito do amor materno, em sua relação com o mito da mãe preta, ao qual Regina Casé permanece vinculada, desde sua atuação no filme Que Horas Ela Volta?. Mesmo diante de tantas continuidades, a atriz diz considerar sua personagem "revolucionária", e explica:

Fiquei muito feliz quando passei a ver negros protagonizando novelas, mas, depois, fiquei pensando assim: "quando que uma mulher da minha idade, com a minha história, fazendo um personagem nordestino, pobre, empregada doméstica, seria protagonista de uma novela das nove na Globo?”. É igualmente revolucionário ${ }^{18}$.

Os limites dessa "revolução", apenas o desfecho da personagem pode mostrar... Lurdes caiu no gosto do público graças ao seu gênio maternal e personalidade resoluta. Disposta a tudo pelos filhos (biológicos e de criação), ela não mede esforços até reencontrar Domênico (Chay Suede), o filho caçula, que foi tirado dela anos atrás. Toda a narrativa gira em torno do drama da mãe em busca de seu filho, e o capítulo do reencontro entre os dois alcançou recordes de audiência.

\footnotetext{
17 As gravações tiveram de ser interrompidas, em meados de 2020, em decorrência da pandemia de Covid 19. A trama foi retomada e finalizada no primeiro semestre de 2021.

18 Fonte: “'Mulher da minha idade fazendo papel nordestino e protagonista é revolucionário', diz Regina Casé". Disponível em: https:/g1.globo.com/pop-arte/noticia/2019/11/13/mulher-da-minha-idade-fazendo-papelnordestino-e-protagonista-e-revolucionario-diz-regina-case.ghtml. Último acesso em maio de 2021.
} 


\section{Intratextes-}

É importante ter em mente que a valorização da maternagem (o trabalho de cuidado) é um caractere essencial das culturas negras (OYĚWÙMÍ, 2021 [1997]; DOVE, 2020 [1998]) ${ }^{19}$. “A valorização da mulher pelas diferentes culturas negro-africanas sempre se deu a partir da função materna" (GONZALEZ, 1981b, p.3). Contudo, devemos frisar que, nessas culturas, as atividades de cuidado não são entendidas como uma atribuição necessária da "mãe", pois o cuidado não se emprega como subsumido ao exercício da maternidade, mas como uma prática voltada para a reprodução da família estendida, ou como responsabilidade familiar básica dos mais velhos para com os mais novos. Na cultura branco-burguesa, por outro lado, as atividades de cuidado serão entendidas como parte da chamada divisão sexual do trabalho e, portanto, como funções femininas, agregadas na figura da "mãe".

Os produtos da Indústria Cultural são um ótimo objeto de análise para que possamos estudar as relações entre cultura, ideologia e modos de dominação. Estes produtos são forjados em consonância com o ethos branco-burguês, uma vez que se apresentam através dos signos elementares da cultura dominante, ao mesmo tempo em que são dotados de elementos dinâmicos, extraídos das culturas subalternizadas. Eles reúnem, deste modo, propriedades habitualmente encaradas como mutuamente excludentes.

A primeira vista, observando o seu viés matriarcal (a família que se conforma a partir da linhagem materna), e de valorização da trajetória da mulher não branca, trabalhadora, com foco no papel materno, pode parecer que Amor de Mãe busca exaltar caracteres provenientes das culturas negro-africanas. Contudo, ao mesmo tempo, a narrativa enfatiza a "maternidade biológica", ou o "vínculo consanguíneo", como o vínculo social mais poderoso de todos, o que vai contra o sentido negro-africano de que a maternagem não está necessariamente relacionada ao fator biológico. A personagem Lurdes não pode jamais desistir do filho gerado de suas próprias entranhas, e compromete-se a recuperá-lo custe o que custar. Enquanto isso, a personagem Thelma (Adriana Esteves), mãe adotiva de Domênico, que cuidou do rapaz durante toda a vida, converte-se em vilã da trama. O sentimento filial que o rapaz nutre pela mãe de criação jamais poderá equiparar-se aos sentimentos "mais genuínos" que sentirá quando conhecer a "mãe verdadeira". A redução do trabalho de cuidado (significado como maternagem) a uma lógica biologizante promove o reforço indireto da divisão sexual do trabalho e, consequentemente, da ideologia de gênero burguesa. O cuidado será apresentado como função

\footnotetext{
19 Nas culturas negro-africanas, a relação social mais importante é entre mãe e filho; em contraste, nas culturas branco-europeias, a relação social mais valorizada é entre "marido e mulher” (OYĚWÙMÍ, 2021; DOVE, 2020).
} 


\section{Intratextes -}

exclusiva da "mãe" (logo, como função feminina) e mais valorizado quando exercido pela "mãe biológica", entendida como "mãe verdadeira".

Lurdes é a "mãe natural", amorosa, abnegada e dedicada aos seus filhos; e é também a "mãe preta", a mãe de criação, não apenas para as crianças que acolhe ao longo de sua trajetória, mas para a patroa Lídia (Malu Galli), uma mulher rica e mentalmente instável, de quem Lurdes se torna "melhor amiga", ajudando-a a recuperar a sanidade. Para os ideólogos do colonialismo, é de praxe retratar as relações de emprego (principalmente relações de emprego doméstico) como permeadas pelo paternalismo. A localização das relações de emprego no âmbito das "relações pessoais" dificulta os avanços no campo do reconhecimento dos direitos trabalhistas.

Retratar os trabalhadores contratados como "quase da família" é uma estratégia comum utilizada pela burguesia para desviar-se do debate acerca da exploração de uma classe de sujeitos por outra.

Os compostos simbólicos da mãe preta e da mulata cordial permanecem circulando ativamente no imaginário da burguesia nacional, sendo largamente exportados para as Américas e para o mundo a cada nova novela comercializada pela Rede Globo. Os temas da doméstica maternal (a mãe preta, o uso físico) e do envolvimento sexual/afetivo entre trabalhadora e patrão (a mulata cordial, o uso sexual) seguem como principais estratégias de inserção da trabalhadora doméstica na fíç̧ão nacional ${ }^{20}$. Para além disso, a personagem da doméstica costuma ser daquelas que vive nas extremidades da narrativa, ou seja, não possui prolongamentos (família, amigos etc), e só existe porque personagens considerados "mais importantes" existem antes dela. São imaginadas, deste modo, como complemento da mulher branca-burguesa. Ao persistir com essa caracterização, a telenovela traz, para o plano material da ficção televisionada, a já exposta ideologia racista que permeia as relações sociais no Brasil.

\footnotetext{
20 Observando as duas últimas trabalhadoras domésticas que receberam destaque (diferente de protagonismo) nas novelas globais, identificamos continuidades que já demonstraram ser estruturais no imaginário dos roteiristas da emissora. Em O Outro Lado do Paraíso (21h, Walcyr Carrasco, 2017), a personagem Raquel (Erika Januza) inicia a trama como uma quilombola que trabalha como doméstica na casa de uma rica família, onde sofre com os ataques racistas da patroa. Como não poderia deixar de ser (dentro do imaginário racista), Raquel se apaixona pelo patrão, e tem de lidar com a frustração de um amor impossível. A partir daí, ela "decide" (como se tudo que lhe impedisse até então fosse a simples livre iniciativa) abandonar o trabalho doméstico, estudar direito e, em uma reviravolta da trama, volta à cidade como juíza. Na novela seguinte, Segundo Sol (21h, João Emanuel Carneiro, 2018), Cacau (Fabíula Nascimento) é uma mulher pobre que ganha dinheiro vendendo refeições nas redondezas da comunidade onde reside. Ela conhece o milionário Edgar (Caco Ciocler), que gosta de sua comida e a convidou para trabalhar como copeira/cozinheira na casa onde vive com os pais e a esposa. Cacau acaba se apaixonando pelo patrão, um homem "sensível e culto", com quem passa a ter um caso.
} 


\section{Intratextes-}

\section{Considerações finais}

Nada é mais representativo do ethos que governa as culturas branco-europeias do que a forma como essas culturas tratam e retratam àqueles que estão localizados fora do seu espectro cultural (ANI, 1994). Observar os modos como as classes branco-burguesas brasileiras compreendem a categoria das trabalhadoras domésticas fornece indícios consistentes para que possamos desmistificar os sistemas simbólicos que sustentam suas ações.

Das 16 atrizes que, interpretando domésticas, protagonizam novelas da Rede Globo, apenas 3 são interpretadas por atrizes não brancas - Taís Araújo ${ }^{21}$ (2012), Camila Pitanga (2012) e Regina Casé (2019). Apenas em 2012, atrizes negras, interpretando trabalhadoras domésticas, protagonizariam novelas da emissora. A despeito da sina imposta a muitas atrizes negras, de sempre interpretarem domésticas, o protagonismo costuma ser dado às atrizes brancas (confira no Quadro 1, ao final do texto). A maior parte das obras concentra-se no horário das $19 \mathrm{~h}$, reservado para as narrativas consideradas mais "leves", de cunho lúdico e festivo. Todos os roteiros foram escritos por pessoas brancas, em sua maioria, homens brancos. Esses roteiristas são provenientes da elite de dois principais estados do país: São Paulo e Rio de Janeiro (confira no Quadro 2, ao final do texto). Observar a origem racial e social destes "produtores de cultura" é fundamental para que possamos perceber os interesses que defendem e o tipo específico de ideologia que reproduzem.

Possuímos, ainda, uma imensa dificuldade em compreender a Indústria Cultural como parte de uma estratégia de dominação. Não é mera coincidência que quatro novelas protagonizadas por domésticas tenham sido lançadas em 2012, ano de apresentação da Proposta de Emenda à Constituição n 66/2012, conhecida como "PEC das Domésticas"; assim como não é mera coincidência o considerável número de reprises de novelas protagonizadas por domésticas que ocorre no ano 2016 (Anjo Mau e Cheias de Charme), logo após a publicação da Lei Complementar 150/2015, que regulamentou a PEC. A veiculação desses produtos em momentos decisivos confere força renovada aos antigos mitos acerca da mulher negra, modulando as possibilidades de ruptura dentro da estrutura de opressão.

\footnotetext{
21 Vale lembrar que a atriz carioca Taís Araújo também foi a primeira mulher negra a protagonizar uma telenovela da Globo (Da Cor do Pecado, 2004), bem como a primeira mulher negra a protagonizar uma novela no Brasil (Xica da Silva, Rede Manchete, 1996). O título Da Cor do Pecado é sugestivo da hiperssexualização reservada ao corpo da mulher negra nesta sociedade. Xica da Silva, por sua vez, foi uma produção que ficou conhecida principalmente devido ao seu teor erótico e provocante.
} 


\section{Intratextos-}

"Ser mulher e negra (ou negra e mulher?) implica ser objeto de um duplo efeito de desigualdade muito bem articulado e manipulado pelo sistema que aí está”, escreve Lélia Gonzalez (1981a, p.8). A autora foi uma das primeiras intelectuais brasileiras a chamar atenção para aquilo que hoje se entende por interseccionalidade. O termo foi cunhado pelo feminismo negro norte-americano, em âmbito acadêmico, na década de 1980, para análise dar "formas cruzadas" de opressão que recaem sobre os sujeitos ${ }^{22}$. O paradigma da interseccionalidade prega que não basta considerar o gênero, mas é preciso examiná-lo em sua interseção com outras variáveis determinantes, como raça e classe ${ }^{23}$. A metodologia interseccional estabelece que não é possível definir uma hierarquia entre as diferentes formas opressões. Não é possível fixar um tipo de opressão como mais importante, ou apontar um determinado eixo como principal articulador. Será mesmo?

Sempre muito perspicaz, Lélia Gonzalez chama atenção para uma peculiaridade da nossa sociedade: aqui, "os efeitos da desigualdade racial são muito mais contundentes que os da desigualdade sexual", e observa que "a divisão racial do trabalho opera de maneira muito mais contundente, em termos de prejuízos para a população negra, do que a divisão sexual do trabalho" (1981a, p.8). Significa dizer que, em termos de distribuição de renda, "a distância que marca as diferenças entre brancas e negras é muito maior do que aquela que separa homens e mulheres" (2018 [1981c], p.51). O que pretendi demonstrar ao longo deste artigo é que, no Brasil, a variável racial tem peso preponderante, exercendo função articuladora/organizadora. Deste modo, o conceito de interseccionalidade pode ser insuficiente para análise de nossa realidade social. Isso porque as mulheres brancas (das classes médias ou do dito "proletariado") localizam-se dento do espectro das culturas branco-europeias, desse modo, o estigma da desumanização, que o ethos da branquitude reserva àqueles que não são identificados como seus semelhantes, não recai sobre elas, mas sim sobre as mulheres negras.

\footnotetext{
22 A este respeito, referencio os artigos de Kimberle Crenshaw (“A Interseccionalidade na Discriminação de Raça e Gênero", 2004) e de Patricial Hill Collins ("Se perdeu na tradução? Feminismo negro, interseccionalidade e política emancipatória", 2017).

$23 \mathrm{O}$ eurofeminismo francófono reivindica a primazia na discussão sobre as formas complexas/combinadas de opressão, alegando que o termo consubstancialidade, cunhado na década de 1970, é anterior à interseccionalidade (a este respeito, referencio o artigo de Danièle Kergoat, "Dinâmica e consubstancialidade das relações sociais", 2006). Não pretendo me aprofundar nas semelhanças e discordâncias entre as duas abordagens teóricas, o caso é que, enquanto a interseccionalidade das feministas negras declara preferência ao par raça/gênero, a consubstancialidade das feministas brancas declara preferência ao par classe/gênero. Para uma comparação entre os paradigmas, veja o artigo de Helena Hirata ("Gênero, classe e raça: interseccionalidade e consubstancialidade das relações sociais", 2014).
} 


\section{Intratextos -}

Conforme demonstrando ao longo deste texto, os papéis que a chamada divisão sexual do trabalho reserva para mulheres brancas e negras é bastante distinto. A liberação da mulher branca das funções domésticas tem ocorrido às custas da exploração da mulher negra, mas este é um tema pouco debatido pelo eurofeminismo. Lélia Gonzalez (1979a) problematiza o fato de que o feminismo costuma tratar abundantemente das relações de dominação homem/mulher. Contudo, quando se trata da mulher negra, o discurso é nublado pelo uso termos como "mulheres pobres" ou "mulheres da classe popular" etc. São as mulheres negras e as famílias negras que constituem a grande maioria nestes grupos, contudo, elas não são caracterizadas como tal, e as denominações utilizadas neutralizam a questão racial. Deste modo, evita-se a questão principal: a exploração de uma raça por outra, e de um grupo de mulheres por outro.

É essa mesma dinâmica de apagamento/esvaziamento que estabelece que, nas telenovelas, as trabalhadoras domésticas que recebem algum grau de protagonismo devem ser preferencialmente interpretadas por atrizes brancas; ao passo que, quanto menor o grau de protagonismo, e quanto mais próxima dos estereótipos da mulata cordial e da mãe preta estiver a personagem, maiores as chances de ela ser interpretada por uma atriz negra. Se a categoria das domésticas é majoritariamente composta por mulheres negras, por que o protagonismo é dado às atrizes brancas? As representações sociais manipuladas pelo racismo cultural são constitutivas do ethos branco-burguês, logo, são visíveis tanto no discurso das feministas brancas, "que não se apercebem de que, no seu próprio discurso, estão presentes os velhos mecanismos do ideal de branqueamento e do mito da democracia racial" (GONZALEZ1979a, p.15), quanto nas obras da Indústria Cultural branco-burguesa.

As telenovelas brasileiras e as produções acadêmicas do eurofeminismo são produtos de um mesmo grupo social (branco-burguês) e frutos de uma mesma matriz cultural. Observálos é o mesmo que se defrontar com o ethos da branquitude. Com um pouco de esforço, é possível visualizar a ideologia por trás das ações, e perceber como esse sistema simbólico reverbera no plano material da vida cotidiana. Reflexo disso são as condições de vida precárias vivenciadas pela população negra em geral, e pela mulher negra em especial. 


\section{Intratextos -}

Quadro 1 - Trabalhadoras domésticas protagonistas em telenovelas da Rede Globo

(1965-2020)

\begin{tabular}{|c|c|c|c|}
\hline Ano & Horário & Título & Atriz \\
\hline 1974 & $19 \mathrm{~h}$ & Supermanoela & Marília Pêra \\
\hline 1975 & $22 \mathrm{~h}$ & Gabriela & Sônia Braga \\
\hline 1976 & $19 \mathrm{~h}$ & Anjo Mau & Susana Vieira \\
\hline 1977 & $19 \mathrm{~h}$ & $\begin{array}{c}\text { Sem lenço, } \\
\text { Sem documento }\end{array}$ & $\begin{array}{l}\text { Arlete Salles, } \\
\text { Isabel Ribeiro, } \\
\text { Ilva Niño, } \\
\text { Ana Maria Braga }\end{array}$ \\
\hline 1997 & $18 \mathrm{~h}$ & $\begin{array}{l}\text { Anjo Mau } \\
\left(2^{\mathrm{a}} \text { versão }\right)\end{array}$ & Glória Pires \\
\hline 2010 & $18 \mathrm{~h}$ & $\begin{array}{c}\text { Escrito nas } \\
\text { Estrelas }\end{array}$ & Nathália Dill \\
\hline \multirow{4}{*}{2012} & $18 \mathrm{~h}$ & Lado a Lado & Camila Pitanga \\
\hline & $19 \mathrm{~h}$ & $\begin{array}{l}\text { Cheias de } \\
\text { Charme }\end{array}$ & $\begin{array}{c}\text { Taís Araújo, } \\
\text { Leandra Leal, } \\
\text { Isabelle Drummond }\end{array}$ \\
\hline & $21 \mathrm{~h}$ & Avenida Brasil & Débora Falabella \\
\hline & $23 \mathrm{~h}$ & $\begin{array}{c}\text { Gabriela } \\
\left(2^{\mathrm{a}} \text { versão }\right)\end{array}$ & Juliana Paes \\
\hline 2019 & $21 \mathrm{~h}$ & Amor de Mãe & Regina Casé \\
\hline
\end{tabular}

Fonte: Quadro elaborado pela autora a partir de informações disponibilizadas nos portais Memória Globo e Gshow Novelas (2021).

Quadro 2 - Autores de telenovelas da Rede Globo protagonizadas por domésticas (19652020) 


\section{Intratextes-}

\begin{tabular}{|c|c|c|c|}
\hline Ano & Horário & Título & Autor/Região \\
\hline 1974 & $19 \mathrm{~h}$ & Supermanoela & $\begin{array}{l}\text { Walter Negrão } \\
\text { (São Paulo) }\end{array}$ \\
\hline 1975 & $22 \mathrm{~h}$ & Gabriela & $\begin{array}{l}\text { Walter Avancini } \\
\text { (São Paulo) }\end{array}$ \\
\hline 1976 & $19 \mathrm{~h}$ & Anjo Mau & $\begin{array}{l}\text { Cassiano Gabus Mendes } \\
\text { (São Paulo) }\end{array}$ \\
\hline 1977 & $19 \mathrm{~h}$ & $\begin{array}{c}\text { Sem lenço, } \\
\text { Sem documento }\end{array}$ & $\begin{array}{l}\text { Mário Prata } \\
\text { (Minas Gerais) }\end{array}$ \\
\hline 1997 & $18 \mathrm{~h}$ & $\begin{array}{l}\text { Anjo Mau } \\
\left(2^{\mathrm{a}} \text { versão }\right)\end{array}$ & $\begin{array}{l}\text { Maria Adelaide Amaral } \\
\text { (Portugal) }\end{array}$ \\
\hline 2010 & $18 \mathrm{~h}$ & $\begin{array}{l}\text { Escrito nas } \\
\text { Estrelas }\end{array}$ & $\begin{array}{l}\text { Elizabeth Jhin } \\
\text { (Minas Gerais) }\end{array}$ \\
\hline \multirow{4}{*}{2012} & $18 \mathrm{~h}$ & Lado a Lado & $\begin{array}{c}\text { João Ximenes Braga, } \\
\text { Claudia Lage } \\
\text { (Rio de Janeiro) }\end{array}$ \\
\hline & $19 \mathrm{~h}$ & $\begin{array}{l}\text { Cheias de } \\
\text { Charme }\end{array}$ & $\begin{array}{l}\text { Filipe Miguez, } \\
\text { Izabel de Oliveira } \\
\text { (Rio de Janeiro) }\end{array}$ \\
\hline & $21 \mathrm{~h}$ & Avenida Brasil & $\begin{array}{l}\text { João Emanuel Carneiro } \\
\text { (Rio de Janeiro) }\end{array}$ \\
\hline & $23 \mathrm{~h}$ & $\begin{array}{c}\text { Gabriela } \\
\left(2^{\mathrm{a}} \text { versão }\right)\end{array}$ & $\begin{array}{l}\text { Walcyr Carrasco } \\
\text { (São Paulo) }\end{array}$ \\
\hline 2019 & $21 \mathrm{~h}$ & Amor de Mãe & $\begin{array}{l}\text { Manuela Dias } \\
\text { (Bahia) }\end{array}$ \\
\hline
\end{tabular}

Fonte: Quadro elaborado pela autora a partir de informações disponíveis nos portais Memória Globo e Gshow Novelas (2021). 


\section{REFERÊNCIAS}

\section{Intratextes-}

ANI, Marimba. Yurugu: An African-Centered Critique of European Cultural Thought and Behavior. New Jersey: Africa World Pr, 1994.

ARAÚJO, Joel Zito. A Negação do Brasil: o negro na telenovela brasileira. $2^{\mathrm{a}}$ ed. São Paulo: Senac, 2004.

BESSE, Susan Kent. Modernizando a desigualdade: reestruturação da ideologia de gênero no Brasil, 1914-1940. São Paulo: Edusp, 1999.

COLLINS, Patricia Hill. Pensamento Feminista Negro: conhecimento, consciência e a política do empoderamento. São Paulo: Boitempo, 2019 [1990].

DOVE, Nah. Mães Afrikanas: portadoras da cultura, desenvolvedoras da mudança social. São Paulo: Medu Neter, 2020 [1998].

FERNANDES, Florestan. A integração do negro na sociedade de classes. Vol. 1: o legado da "raça branca". São Paulo: Globo, 2008 [1964].

FREYRE, Gilberto. Casa-grande \& Senzala: formação da família brasileira sob o regime de economia patriarcal. $48^{a}$ ed. São Paulo: Global, 2003 [1933].

GONZALEZ, Lélia. Cultura, etnicidade e trabalho: efeitos linguísticos e políticos da exploração da mulher. Comunicação apresentada no VIII Encontro Nacional da Latin American Studies Association. Pittsburgh, Pensilvânia, USA, 5 a 7 de abril de 1979a.

. A juventude negra brasileira e a questão do desemprego. Resumo apresentado na Segunda Conferência Anual do African Heritage Studies Association. 26 a 29 de abril de $1979 \mathrm{~b}$.

. Mulher Negra. Mulherio. Ano I, No 3, setembro/outubro de 1981a.

. Democracia racial? Nada disso!. Mulherio. Ano I, $\mathrm{N}^{\circ} 4$, novembro/dezembro de $1981 b$.

. A mulher negra na sociedade brasileira: uma abordagem políticoeconômica. In: Primavera para as rosas negras. Editora Filhos da África, 2018 [1981c]. v. 2, n. 1, p. 223-244, 1984 .

Racismo e sexismo na cultura brasileira. Revista Ciências Sociais Hoje,

HAMBURGER, Esther. O Brasil antenado: a sociedade da novela. Rio de Janeiro: Zahar, 2005. 


\section{Intratextes-}

KEHL, Maria Rita. Eu vi um Brasil na TV. In: KEHL, M. R.; COSTA, A. H.; SIMÕES, I. F. (Orgs.). Um país no ar: histórias da TV brasileira em três canais. São Paulo/Rio de Janeiro: Brasiliense/Funarte, 1986.

MACEDO, Renata. Espelho mágico: empregadas domésticas, consumo e mídia. Dissertação apresentada ao Programa de Pós-graduação em Antropologia da USP. São Paulo, 2013.

NASCIMENTO, Beatriz. A mulher negra no mercado de trabalho. Jornal Última Hora, Rio de Janeiro, julho de 1976.

OYĚWÙMÍ, Oyèrónké. A invenção das mulheres: construindo um sentido africano para os discursos ocidentais de gênero. Rio de Janeiro: Bazar do tempo, 2021 [1997].

RONCADOR, Sônia. A Doméstica imaginária: literatura, testemunhos e a invenção da empregada doméstica no Brasil (1889-1999). Brasília: Editora UnB, 2008.

SARRIS, Georgia; FILLETI, Juliana; CARDOSO de MELO, Maria Fernanda; GORAYEB, Daniela. Perfil das Empregadas Domésticas no $1^{\circ}$ trimestre de 2020: dados selecionados. In: Estudos NPEGen. Campinas: Editora FACAMP, № 02, agosto de 2020.

SOUZA, Florentina; DALBETO, Lucas. Patroas vs empregadas: o conflito das classes retratado nas telenovelas. Logos - dossiê "realidade e ficção". Vol.20, no 01, 2013.

Recebido em: Junho de 2021 Aprovado em: Outubro de 2021. 